\title{
Experiences of patients with age-related macular degeneration receiving anti-vascular endothelial growth factor therapy: $A$ qualitative study.
}

\author{
Burton, A. E., Shaw, R. L. \& Gibson, J. M. (2013).
}

British Journal of Vision Impairment, 31(3), 178-188.

\section{Abstract}

The societal cost for the average health authority in the United Kingdom for the care of wet age-related macular degeneration (AMD) has been suggested to be around $£ 7.4$ million. It is vital that the best possible care based on the best available evidence is provided to reduce the impact of AMD on patients' lives and the financial cost to the health-care system. This study explored the experiences of AMD patients treated with intravitreal ranibizumab injections. Three semi-structured interviews were conducted with seven participants over the course of 18 months. Transcripts were analysed using interpretative phenomenological analysis. Analysis identified four themes: preparing for treatment, the treatment process, patient-provider communication, and results of treatment. Patient experiences highlighted the need to move away from the reliance on letters for information provision, and the need for clearer guidelines about when to cease AMD treatment. Interviews highlighted the need for the inclusion of rigorous qualitative evidence with experiential data in future good clinical practice guideline development for AMD.

Keywords: anti-vascular endothelial growth factor; macular degeneration; patient experience; vision loss

\section{Introduction}

Age-related macular degeneration (AMD) is one of the most common causes of vision impairment in older people (Bunce \& Wormald, 2006). Patients suffer from decreased quality of life, decreased well-being, increased psychological distress, and greater health-related disability (Augustin et al., 2007; Berdeaux, Nordmann, Colin, \& Arnould, 2005; Brody et al., 2001; Chia et al., 2004; Esteban et al., 2008; Williams, Brody, Thomas, Kaplan, \& Brown, 1998), all comparable with other serious illnesses (Williams et al., 1998). AMD patients report functional limitations, issues with adaptation and independence, concerns about the future, problems interacting with health services, issues with social engagement, and concern about whether to disclose AMD to others (Bennion, Shaw, \& Gibson, 2012).

Untreatable dry AMD accounts for between $80 \%$ and $90 \%$ of cases, while wet treatable AMD accounts for between 10\% and 20\% (Bourla \& Young, 2006). The societal cost for the average health authority in the United Kingdom for the care of wet AMD has been suggested to be around $£ 7.4$ million compared to only $£ 1$ million for comparable patients without wet AMD (Lotery, Xu, Zlatave, \& Loftus, 2007). It is therefore vital that patients receive the best possible care based on the best available evidence to reduce the impact of the condition on patients' lives and the financial cost to the health-care system. In the United Kingdom, guidelines for AMD treatment have been published by the Royal College of Ophthalmologists (RCOphth), the National Institute for Health and Clinical Excellence (NICE), and in Scotland, by the Scottish Intercollegiate Guidelines Network (SIGN) (NICE, 2008; RCOphth, 2009; SIGN, 2012). NICE guidelines recommend antivascular endothelial growth factor (anti-VEGF) therapy treatments for wet AMD patients, which can transform visual outlook with $40 \%$ gaining some improvement in vision and 90\% maintaining current levels (Brown et al., 2009). As no clear protocol currently exists, NICE (2008) recommended that guidelines be developed for the discontinuation of treatment in patients with belowadequate response to therapy and that further research be conducted assessing the long-term effects of treatment with particular focus on visual acuity, anatomical damage to the macula, adverse events, and quality of life (NICE, 2008).

Traditionally, practice guidelines have been informed by randomised clinical trials (RCTs). More recently, practitioners have begun to acknowledge that RCTs are unable to answer many of the questions necessary for improving practice. Therefore, other forms of evidence can and should contribute to the knowledge base (Shaw, 2012). For example, qualitative data can be used to inform ophthalmology practice (Hayeems, Geller,

Cite as: Burton, A. E., Shaw, R. L. \& Gibson, J. M. (2013). Experiences of patients with age-related macular degeneration receiving anti-vascular endothelial growth factor therapy: A qualitative study. British Journal of Vision Impairment, 31(3), 178-188. 
Finklestein, \& Faden, 2005; McLean, Windridge, \& Gottlob, 2012). By incorporating in-depth, transparent, and systematic qualitative work, it is possible to use patient's experiential knowledge to inform practice guidelines (Kelly et al., 2009). In addition, longitudinal qualitative data collection has numerous benefits, including the ability to build rapport with participants and the recognition that life experiences are dynamic entities that change over time (Lawton, Peel, Parry, \& Douglas, 2008). This study investigates the subjective experiences of patients treated with a anti-VEGF injections (Lucentis) using a series of three interviews over a period of 18 months.

\section{Materials and methods}

\section{Participants}

The data reported are from a sub-sample of seven patients with wet AMD amenable to treatment selected from a wider mixed-methods study investigating the impact of treatable and untreatable AMD on quality of life (Burton, 2012). The seven participants reported in this article were the only participants with treatable AMD in the qualitative arm of the mixed-methods study. Recruitment occurred at two specialist macular disease clinics in central England. Clinic ophthalmologists identified new wet AMD patients between May and July 2010. Patients who expressed interest in participating were contacted by phone to arrange the first of the three interviews over 18 months.

\section{Interviews}

Face-to-face interviews, which lasted between 1 and $2.5 \mathrm{hr}$, were completed at three time points over 18 months. The first interview was completed as soon after recruitment as possible, the second at 9 months postrecruitment, and the third at 18 months post-recruitment. We aimed to conduct the first interview prior to any treatment taking place; however, due to the short time period between diagnosis and first treatment, this was not possible for some participants. Most participants completed three interviews; however, two could not be contacted for the third interview. All interviews took place in the participants' own homes.

Initial interviews were based on a semi-structured schedule, which included questions about experiences of diagnosis, impacts on daily activities, relationships with family and friends, and thoughts about the future. Later interviews began with the open question 'how have things been since the last time we met?' in order to expand upon previous accounts and ensure that interviews were led by participant experiences. All interviews were audio-recorded and transcribed verbatim.

\section{Data analysis}

A thematic account of the participants' experiences was produced using interpretive phenomenological analysis (IPA; Smith \& Osborn, 2008). Analysis was an iterative and cyclical process involving a constant movement back and forth between the levels of analysis (Shin, Kim, \& Chung, 2009). IPA is based on the philosophical traditions of existential phenomenology and hermeneutics and aims to explore the lived experience and sensemaking process exemplified in participants' accounts (Smith \& Osborn, 2008).

IPA involves a double hermeneutic, which means that the analyst is interpreting the participants' interpretations of their experience (Smith \& Osborn, 2008). Each transcript was read several times to develop a holistic understanding of accounts. Transcripts were annotated with unfocused notes relating to elements that appeared to be interesting or of significance to the participants' meaning making. The text was then read in small sections (or meaning-units) (Langdridge, 2007), and descriptive summaries were produced. Theme titles were developed based on the original text, descriptive summaries, and unfocused notes. Themes were then clustered under conceptual headings. This process was repeated for the first and second interviews. Elements of the final interviews, which represented new information or changes in experience, were highlighted and notes made. All relevant data extracts for each theme were collated and used to develop a narrative account.

\section{Results}

\section{Participant characteristics}

Demographic data can be found in Table 1. All participants were allocated pseudonyms.

Preparing for treatment. Participants described preparing for treatment. At the first interview, Rose's awareness that treatment involved an injection into the eye resulted in anxiety, fear, and uncertainty. By the second interview, numerous appointments and the discovery that treatments were not as distressing as originally feared meant Rose no longer looked back on her first treatments as an anxious time:

Cite as: Burton, A. E., Shaw, R. L. \& Gibson, J. M. (2013). Experiences of patients with age-related macular degeneration receiving anti-vascular endothelial growth factor therapy: A qualitative study. British Journal of Vision Impairment, 31(3), 178-188. 
[Treatment] never worried me at all when I went the first time you know? Because you didn't know what you'd got to come, but it worries you a little but, you know? You are a little bit apprehensive . . . People would say, 'oh, I couldn't do that, I should be frightened to death!' but I'm not a nervous disposition so it doesn't ... upset me that much. (Rose, Interview 2)

Table 1: Participant demographic data

\begin{tabular}{|c|c|c|c|c|c|c|}
\hline Pseudonym & Age & Gender & Diagnosis & $\begin{array}{l}\text { Visual a } \\
\text { Best eye }\end{array}$ & $\begin{array}{l}\text { ity } \\
\text { Worst eye }\end{array}$ & $\begin{array}{l}\text { Number } \\
\text { of } \\
\text { interviews }\end{array}$ \\
\hline Alison & 85 & Female & $\begin{array}{l}\text { Wet AMD } \\
\text { in both } \\
\text { eyes }\end{array}$ & $6 / 9$ & $9 / 12$ & 3 \\
\hline Irene & 86 & Female & $\begin{array}{l}\text { Wet AMD } \\
\text { in on eye \& } \\
\text { dry AMD in } \\
\text { other }\end{array}$ & $6 / 7.5$ & $6 / 30$ & 2 \\
\hline Rose & 89 & Female & $\begin{array}{l}\text { Wet AMD } \\
\text { in one eye } \\
\& \text { dry AMD } \\
\text { in other }\end{array}$ & $6 / 9$ & $6 / 12$ & 2 \\
\hline Nuxy & 78 & Male & $\begin{array}{l}\text { Wet AMD } \\
\text { in one eye } \\
\& \text { dry AMD } \\
\text { in other }\end{array}$ & $6 / 7.5$ & $6 / 12$ & 3 \\
\hline Ruffine & 82 & Female & $\begin{array}{l}\text { Wet AMD } \\
\text { in one eye } \\
\& \text { no Mad } \\
\text { in other }\end{array}$ & $6 / 6$ & $6 / 24$ & 3 \\
\hline Jordan & 75 & Female & $\begin{array}{l}\text { Wet AMD } \\
\text { in both } \\
\text { eyes }\end{array}$ & $6 / 36$ & $6 / 60$ & 3 \\
\hline Rick & 82 & Male & $\begin{array}{l}\text { Wet AMD } \\
\text { in one eye } \\
\& \text { no AMD } \\
\text { in other }\end{array}$ & $6 / 9.5$ & $6 / 19$ & 3 \\
\hline
\end{tabular}

Similarly, when Rick had no one to ease his concerns at first treatment, he sat alone and worried in the waiting room. However, at a later appointment, Rick was able to use his prior knowledge and experience of treatment to ease concerns of another patient:

On the last treatment ... there was [an] older lady ... there with her husband and she was ... [nervous] like you know, obviously . . . they said, 'what's it like', and I said, 'your first one?' . . I'd had two or three, and I said, 'no, there's no pain' I said, 'it's a funny sensation, and you feel a bit squeezy when you go in and you see the chair there, and you see them with the masks on', that's what frightens - frightens people I think. I said, 'there's a funny sensation, just a funny sensation' and 'I said there's no need to worry, no pain, definitely no pain' . . . she went in before me and when she come out her husband went, 'thanks', I said 'it's alright, it's no problem', and you know, I'm glad I could have put somebody at ease, I had nobody to tell me that ((laughs)) I was the only one there that night, funny that, I was the only one in the waiting room that night ... I was the same as that lady, a needle in my eye! You know? (Rick, Interview 2)

Imaginations of treatment could be more distressing than the reality, which is an important issue as patients may decline treatment due to fear. Ensuring patients are fully informed may help to ease concerns and reduce unnecessary distress.

The treatment process. Treatment was described as a fairly uniform process. Alison's account was typical of the participants' descriptions of undergoing treatment:

Cite as: Burton, A. E., Shaw, R. L. \& Gibson, J. M. (2013). Experiences of patients with age-related macular degeneration receiving anti-vascular endothelial growth factor therapy: A qualitative study. British Journal of Vision Impairment, 31(3), 178-188. 
You have a cap on and so you obviously lie down and they put the sides [of the operating table] up and, then [the doctor] appears, ... and she sort of, if you, if you visualise it feels like a clamp which your eyelids are clamped open and then they bring the big light over the operating table ... which sort of makes you think well, I wish I could shut my eyes ... and then of course she puts the needles in, which you do feel and you can also feel, see the liquid when it's coming, go across your eye, you see the liquid go across, and of course it's essential that you've usually got a nurse either side of you because you've got to put your arms down in case you suddenly put your hand up ... (Alison, Interview 1)

Alison's account was highly descriptive and helped to build a picture of what the experience of treatment may be like. In the absence of embodied knowledge, we can only draw on images within our experience to make sense of what may happen to us, and we therefore may create images that are more anxiety provoking than the actual experience. This may also help to explain why Rose and Rick found the anticipation of being treated more distressing than the actuality. In hindsight, almost all of the patients asserted that treatment was worth the initial distress and urged others diagnosed with AMD to accept treatment if it was offered to them:

Just don't worry about it and accept the treatment because if you don't you are not going to get any better are you? (Rick, Interview 3)

Some participants described building relationships with nurses as a way to manage the distress treatment caused. Alison explained that holding nurses hands was reassuring physical contact as well as performed the function of keeping hands away from her eyes during treatment:

It is scary going in to hospital, it is, so when you get to know all the staff and the staff know you, and it is, and they are all, I don't know how many people who's hand I've held, because they all do that, and I might tell you, it is very very good, because when the initial thing goes, the needle is there, you do, and you grip you know? And so it mightn't sound much when the nurses do it, but it is very important, very important, because you do grab the hand, I mean, it doesn't last for long but it's quite scary. (Alison, Interview 2)

Ruffine used jokes with nurses as a self-calming strategy to distract her from the treatment procedure and reduce the amount of anxiety that would be felt if her full attention was focused on treatment:

It doesn't worry me at all. I'm not, in fact, whether it's nerves or not I don't know, but I joke. I joke a lot with the nurse in case, in fact one of them said, 'oh, it's her the jokey foreigner again' ((laughs)) and that's what they call me ((laughs)) . . I I joke with them, so it passes, it doesn't worry me one bit. (Ruffine, Interview 2)

As friends and family are not permitted in treatment rooms, friendship-like relationships with nurses may help to ease distress.

Health-care professional-patient communication. Hospital appointments involving multiple tests and interactions with a variety of health-care professionals (HCPs) could be confusing. Participants described undergoing tests and scans with no knowledge of their purpose. Ruffine felt undervalued by HCPs when even basic introductions were overlooked:

I didn't see the reason why there were so many different people that I had to go and see individually, I mean the same nurse could have come and done, put ... the injection in my arm, she could have come and took it out... you were going from one place to another, and you waited, another place to another, then you waited, another place to another, then you waited ... when I asked, for someone to come and take this [needle] out at the end, one young lady came and she took my blood pressure, I'd finished then, and I said 'are you going to take this?', 'no you'll have to wait for a nurse'. (Ruffine, Interview 1)

Confusion could also develop over time as getting information to patients was often slow. Nuxy became anxious when he realised that he lacked information about what was happening within his own body:

... all I want now is some contact from the hospital to say what's happening next, . . . it's been five days basically and I haven't heard a word yet ... I mean there could be things they could be doing now to, to make sure that it doesn't deteriorate too quickly, but I don't know nothing, I don't know nothing apart from, we'll get in touch with you, that's all I know basically. (Nuxy, Interview 1)

Nuxy's search and desire for information represented his attempt to regain control in a time of uncertainty when knowledge was the only source of power. A lack of suitable and timely information could exacerbate the confusion experienced, and a more personal relationship with HCPs involving two-way communication may help to combat this:

[the ophthalmologist said] 'my name is Mr so and so, I'm pleased to meet you'. I said, 'well I'm not pleased to see Cite as: Burton, A. E., Shaw, R. L. \& Gibson, J. M. (2013). Experiences of patients with age-related macular degeneration receiving anti-vascular endothelial growth factor therapy: A qualitative study. British Journal of Vision Impairment, 31(3), 178-188. 
you', like you know? And he laughed and we went in ... He asked, 'are you taking your drugs?' And I said 'yes', I said 'morning and night', and he said, 'the morning ones' he said, you can take that twice' . . but he was the only one that asked me if I was taking the drops funnily enough. (Rick, Interview 2)

Communication could also be affected by other age-related factors. For example, hearing loss is a common occurrence in old age and can dramatically affect ability to communicate. Rick described the emotional impact this could cause, as he found himself in an uncomfortable situation where he desired information but at the same time did not want to create a nuisance of himself by asking the doctor to repeat information:

I couldn't understand that doctor ... I couldn't understand her properly 'cause she's speaks too quick for me ... I'm slightly hard of hearing in this ear and I must be slow at picking it up like that . . I kept having to say, 'Sorry could you repeat that'. I don't like keep doing that to people. I think it's rude, well it's not rude, I can't help it. But I don't like doing that like you know, and she was getting annoyed with me. Wasn't she? (Rick, Interview 1)

Rick's account also hinted that he did not have enough information to provide informed consent for his treatment. This lack of knowledge left him powerless, and his only option was to adopt the role of submissive patient:

It seemed like they were photographing my eyes, there was a flash, I presume that was it. Because jokingly, I said what was that and I said well you could have said smile like you know and she looked at me as if I'm barmy ... But then I went to, I think it was about 4 or 5 different places, which, well they know what they're doing. It's no use me arguing about it is it? (Rick, Interview 1)

Rick attempted to make light of this by joking with the HCPs, but the reaction Rick received only served to add to his anxiety and left Rick continuing to feel confused. This highlights how patients may not be sufficiently engaged in decisions about their care or informed about their choices.

Participants commented on problems with hospital appointment letters, which gave little information about what each appointment was for and what the participant should expect. Patients undergo a scan every month to check whether further injections are required and receive a letter inviting them to the scan and, if needed, a second letter inviting them for treatment. On many occasions, these letters were sent together, which caused confusion. Ruffine described the number of appointment letters she received and, based on past experiences of hospital mistakes, had assumed this may also be a mistake:

when I read all this [in the letters] . . I thought they've sent me all these [appointments] all at once, have they slipped up? Which one am I supposed to have? . . Because I know they do slip up at hospitals because at the orthopaedic hospital, they sent me a, the follow up of what the scans going to be before I had and appointment for the scan! ((laughs)) ... I thought well this is ridiculous! (Ruffine, Interview 1)

Some participants with poorer vision needed to rely on family members to relay the information in letters also suggesting that this form of communication may not be the most suitable way to ensure information is kept confidential and acted upon by patients.

Patients preferred appointments that exemplified balanced relationships, mutual respect, and professional friendship and that left them feeling empowered about decisions they could make regarding treatment and management of their condition.

Results of treatment. Participants were unsure about when their treatment cycle would end. Treatment had become a routine part of life, and participants seemed to accept that injections may be needed indefinitely. However, there were examples of patients attempting to make their own judgements about the need for treatment. Ruffine had been testing her eyes by looking at the television in order to assess the effects of treatment and assumed her vision may be continuing to deteriorate:

I can't really say [my vision has] improved a lot, because when I look at the TV, I don't need my glasses for the $\mathrm{TV}$, in fact I don't read a lot now because I can tell I need stronger glasses. But when I look at the TV without my glasses, if I close the bad eye I can see perfectly, if I close the good eye, I can see to a certain extent but I can't distinguish the features, the faces. So I know that I'll probably need more injections. (Ruffine, Interview 2)

The day-to-day impact of the condition and the improvements treatment may make to this were the most important issues for participants. During hospital appointments, some were given indications of the clinical improvements treatment was having. Both Irene and Jordan had been told that the 'lump' resulting from AMD had been reduced by treatment:

Cite as: Burton, A. E., Shaw, R. L. \& Gibson, J. M. (2013). Experiences of patients with age-related macular degeneration receiving anti-vascular endothelial growth factor therapy: A qualitative study. British Journal of Vision Impairment, 31(3), 178-188. 
The vision and everything, has gone a bit, quite a bit better you know? Quite good I've been quite pleased with it. The last fortnight I think there was [an appointment], and [the ophthalmologist] said, . . 'come and have a look at this now [Irene]', she'd got [the scan] on the laptop, and there was a line going down and there was a bump across, sort of enlarged bump like that, and she said, 'that's before and after', and there was just a slight little bump, and she said, 'we are very pleased with the way it's, you've responded to the treatment'. So I was very pleased with that. (Irene, Interview 2)

They gave me the injections like to get rid of that lump at the back of my eye. Which they have done, they said it's gone now, so you don't have to have no more treatment, and that's what I thought, if I've got to have no more treatment why didn't they put me straight onto glasses? (Jordan, Interview 2)

While Irene's daily experiences fitted well with the clinical changes that were described to her by HCPs (i.e., she could now see faces on photographs, read the clock on her mantelpiece etc.), Jordan's daily experiences did not suggest improvements. The reduction of the lump made sense to Irene as an indication of her improvements. In contrast, Jordan struggled to understand how her treatment could have been a success when the HCPs seemed pleased that she had shown clinical improvements to the point where she was no longer to have further treatment, while she experienced no improvements in her day-to-day life.

All of the participants highlighted a sense of uncertainty about the future. Some described fear of further deterioration and the loss of activities they enjoyed, while others spoke of hope that treatment may improve their vision and approached thoughts about the future with attempts to accept their circumstances:

[the ophthalmologist] said that [my eyes] should go back to what they were normally so I'm hoping. (Rose, Interview 1)

I don't really know [what my vision will be like in the future], I hope that it's going to be better, but I can't see that, but as long as they are giving me the injections and that's supposed to stop you from going blind, so I'm hoping that it's going to be alright. (Rose, Interview 2)

At the first interview, Rose spoke about hope that she would see improvements in her vision following treatment; however, by the second interview, Rose had not experienced improvements, and this increased the uncertainty she felt about her future. In order to cope, Rose reassessed her priorities and focused her hopes on maintaining the vision she had. For Rose, vision impairment seemed to be a 'black and white' construct in which she was either sighted or blind, and Rose assumed that if the injections failed, then there would be nothing preventing her from complete blindness. This again illustrates the need for clearer communication with patients to enable them to develop realistic expectations about their prognosis and avoid unnecessary distress.

\section{Limitations}

This exploratory study provides an important insight into an under-researched area within the experience of patients with AMD. While the sample size for this study is small, this is not uncommon in qualitative research of this type. However, it is important to highlight that the accounts presented are those of volunteers, and therefore, their experiences may not be representative of the potential responses of those who did not volunteer to be part of the study.

\section{Discussion}

What can ophthalmologists and hospital eye clinics treating AMD learn from patients' experiences? Almost all the patients in this sample asserted that treatment was worth any distress it may cause and urged others to accept treatment when offered. Treatment represented the possibility, and for some the actuality, of improved vision. Despite this initial thought about treatment could be distressing and more could be done to reduce unnecessary worries prior to treatment. Rick's example of providing support to another patient illustrates that simply preparing the patients for what to expect could result in reduced anxiety, and suggests that hospital units could actively identify 'expert patients' who would be able to advise the newly diagnosed. Ophthalmologists should be aware that some patients may choose not to attend treatments out of anxiety about the process. Easing the concerns of these patients would ensure that treatment is sought by all who can benefit from it.

Eye clinics and ophthalmic staff are under huge pressure to deliver services, and with increasing patient numbers, consultation time with individual patients is necessarily limited. However, above all else, this study shows that time spent with patients alleviating their concerns is vital for their emotional well-being, and in our experience, a contact person for counselling, outside of the normal clinic visit, may be a solution to this problem. Current guidelines for practice are particularly focused on decisions regarding treatment provision. The NICE (2008) treatment guidelines use objective clinical measures (i.e., visual acuity) as the basis for Cite as: Burton, A. E., Shaw, R. L. \& Gibson, J. M. (2013). Experiences of patients with age-related macular degeneration receiving anti-vascular endothelial growth factor therapy: A qualitative study. British Journal of Vision Impairment, 31(3), 178-188. 
decisions about treatment; however, the patients themselves may make different treatment decisions based on their daily experiences. This is further evidence for the need for guidelines regarding the cessation of treatment to be developed. In addition, clear guidelines with regard to assisting patients with the emotional impacts of the condition are required.

While the guidelines produced by the RCOphth (2009) have gone some way to improving the experience of patients in terms of communication with HCPs, they are based on the clinical experience of experts in the field who have used their own observations to develop recommendations. In light of the data presented here, it appears that the recommendations are insufficient in terms of the experiences of patients themselves. There appears to be an over-reliance on written information, and it would seem that these methods are not suitable for many who find reading difficult due to their visual impairment. Other research has also indicated that, for individuals with visual impairment, leaflets may not be the most suitable medium for the delivery of information forcing individuals to seek information elsewhere (Lawton et al., 2008). Even practitioners acknowledge that letters may be unsuitable for many patients (Goyder, Carlisle, Lawton, \& Peters, 2009). Alternatives, such as telephone help lines, may be an easy and relatively inexpensive means of providing access to information (Goyder et al., 2009; Raynor, 1994). This is an example of where expert opinion and patient experience differ and highlights the need for the incorporation of experiential patient data when developing guidelines for practice.

Patients were often forced to rely on their HCPs' judgements due to their own lack of knowledge. This raises questions regarding 'informed consent' as often patients accept HCPs' decisions regarding their health as they are perceived to be the experts (Goyder et al., 2009). This is a failing of the traditional medical model of health care, which positions patients as 'passive'. More recently, 'patient-centred' approaches have gone some way to change this by empowering patients and giving them an element of 'choice' (Department of Health, 2005). This could be taken further by acknowledging that HCPs have clinical and technical knowledge, while patients have experiential knowledge of what it is like for them to live with the condition and both should be incorporated within guidelines for practice (Dahlberg, Todres, \& Galvin, 2009).

\section{Funding}

This research received support from the Aston Research Centre for Healthy Ageing, Aston University.

\section{References}

Augustin, A., Sahel, J. A., Bandello, F., Dardennes, R., Maurel, F., Negrini, C., . . Berdeaux, G. (2007). Anxiety and depression prevalence rates in age-related macular degeneration. Investigative Ophthalmology \& Visual Science, 48, 1498-1503.

Bennion, A. E., Shaw, R. L., \& Gibson, J. M. (2012). What do we know about the experience of age related macular degeneration? A systematic review and meta-synthesis of qualitative research. Social Science \& Medicine, 75, 976-985.

Berdeaux, G. H., Nordmann, J. P., Colin, E., \& Arnould, B. (2005). Vision-related quality of life in patients suffering from age-related macular degeneration. American Journal of Ophthalmology, 139, 271-279.

Bourla, D. H., \& Young, T. A. (2006). Age-related macular degeneration: A practical approach to a challenging disease. Journal of the American Geriatrics Society, 54, 1130-1135.

Brody, B. L., Gamst, A. C., Williams, R. A., Smith, A. R., Lau, P. W., Dolnak, D., . . Brown, S. I. (2001). Depression, visual acuity, comorbidity, and disability associated with age-related macular degeneration. Ophthalmology, 108, $1893-1900$.

Brown, D. M., Michels, M., Kaiser, P. K., Heier, J. S., Sy, J. P., \& Ianchulev, T. (2009). Ranibizumab versus verteporfin photodynamic therapy for neovascular age-related macular degeneration: Two-year results of the ANCHOR study. Ophthalmology, 116, 57-65.

Bunce, C., \& Wormald, R. (2006). Leading causes of certification for blindness and partial sight in England and Wales. BMC Public Health, 6, 58.

Burton, A. E. (2012). The experience of living with age related macular degeneration: A longitudinal study into the impact of age related macular degeneration on quality of life. PhD Thesis, Aston University, Birmingham, UK.

Chia, E. M., Wang, J. J., Rochtchina, E., Smith, W., Cumming, R. R., \& Mitchell, P. (2004). Impact of bilateral visual impairment on health-related quality of life: The Blue Mountains Eye Study. Investigative Ophthalmology \& Visual Science, 45, 71-76.

Dahlberg, K., Todres, L., \& Galvin, K. T. (2009). Lifeworld-led healthcare is more than patient-led care: An existential view of well-being. Medicine Healthcare and Philosophy, 12, 265-271.

Department of Health. (2005). Creating a Patient-led NHS: Delivering the NHS improvement plan. London: Department of Health.

Esteban, J. J. N., Martinez, M. S., Navalon, P. G., Serrano, O. P., Patino, J. R. C., Puron, M. E. C., \& Martínez-Vizcaíno, V. (2008). Visual impairment and quality of life: Gender differences in the elderly in Cuenca, Spain. Quality of Life Research, 17, 37-45.

Cite as: Burton, A. E., Shaw, R. L. \& Gibson, J. M. (2013). Experiences of patients with age-related macular degeneration receiving anti-vascular endothelial growth factor therapy: A qualitative study. British Journal of Vision Impairment, 31(3), 178-188. 
Goyder, E., Carlisle, J., Lawton, J., \& Peters, J. (2009). Informed choice and diabetes screening in primary care: Qualitative study of patient and professional views in deprived areas of England. Primary Care Diabetes, 3, 85-90.

Hayeems, R. Z., Geller, G., Finklestein, D., \& Faden, R. R. (2005). How patients experience progressive loss of visual function: A model of adjustment using qualitative methods. British Journal of Ophthalmology,89, 615-620.

Kelly, M. P., Stewart, E., Morgan, A., Killoran, A., Fischer, A., Threlfall, A., \& Bonnefoy, J. (2009). A conceptual framework for public health: NICE's emerging approach. Public Health, 123, 14-20.

Langdridge, D. (2007). Phenomenological psychology: Theory, research and method. Harlow, UK: Pearson Education.

Lawton, J., Peel, E., Parry, O., \& Douglas, M. (2008). Shifting accountability: A longitudinal qualitative study of diabetes causation accounts. Social Science \& Medicine, 67, 47-56.

Lotery, A., Xu, X., Zlatave, G., \& Loftus, J. (2007). Burden of illness, vision impairment and health resource utilisation of patients with neovascular age-related macular degeneration: Results from the UK cohort of a five-country crosssectional study. British Journal of Ophthalmology, 91, 1301-1307.

McLean, R. J., Windridge, K. C., \& Gottlob, I. (2012). Living with nystagmus: A qualitative study. British Journal of Ophthalmology, 96, 981-986.

National Institute for Health and Clinical Excellence. (2008). Ranibizumab and pegaptanib for the treatment of age-related macular degeneration. London, England: Department of Health.

Raynor, D. K. (1994). Dial M for medicine advice. Health Services Journal, 104, 33.

The Royal College of Ophthalmologists. (2009). Age related macular degeneration: Guidelines for management. London, England: Author.

Scottish Intercollegiate Guidelines Network. (2012). Published guidelines. Edinburgh, Scotland: Health Improvements Scotland.

Shaw, R. L. (2012). Identifying and synthesising qualitative literature. In D. Harper \& A. R. Thompson (Eds.), Qualitative research methods in mental health and psychotherapy: A guide for students and practitioners (pp. 227-243). Chichester, UK: Wiley-Blackwell.

Shin, K. R., Kim, M. Y., \& Chung, S. E. (2009). Methods and strategies utilized in published qualitative research. Qualitative Health Research, 19, 850-858.

Smith, J. A., \& Osborn, M. (2008). Interpretative phenomenological analysis. In J. A. Smith (Ed.), Qualitative psychology: A practical guide (2nd ed., pp. 51-80). London, England: SAGE.

Williams, R. A., Brody, B. L., Thomas, R. G., Kaplan, R. M., \& Brown, S. I. (1998). The psychosocial impact of macular degeneration. Archives of Ophthalmology, 116, 514-520. 